\title{
BMJ Open Indwelling urinary catheters, aortic valve treatment and delirium: a prospective cohort study
}

\author{
Leslie SP Eide, ${ }^{1}$ Anette H Ranhoff, ${ }^{2,3}$ Sandra Lauck, ${ }^{4,5}$ Bengt Fridlund, ${ }^{6}$ \\ Rune Haaverstad, ${ }^{2,6}$ Karl Ove Hufthammer, ${ }^{7}$ Karel K J Kuiper, ${ }^{6}$ \\ Jan Erik Nordrehaug, ${ }^{2,8}$ Tone Merete Norekvål, ${ }^{1,2,6}$ On behalf of the CARDELIR \\ Investigators
}

To cite: Eide LSP, Ranhoff AH, Lauck S, et al. Indwelling urinary catheters, aortic valve treatment and delirium: a prospective cohort study. BMJ Open 2018;8:e021708. doi:10.1136/ bmjopen-2018-021708

- Prepublication history for this paper is available online. To view these files, please visit the journal online (http://dx.doi. org/10.1136/bmjopen-2018021708).

Received 19 January 2018 Revised 23 May 2018 Accepted 5 October 2018
Check for updates

(c) Author(s) (or their employer(s)) 2018. Re-use permitted under CC BY-NC. No commercial re-use. See rights and permissions. Published by BMJ.

For numbered affiliations see end of article.

Correspondence to

Dr Leslie SP Eide;

leslieeide@hotmail.com

\section{ABSTRACT}

Objectives To determine whether an association exists between delirium and length of time indwelling urine catheters (IUC) are used in octogenarian patients treated with surgical aortic valve treatment (SAVR) or transcatheter aortic valve implantation (TAVI).

Design Prospective cohort study.

Setting Tertiary university hospital covering the western region of Norway.

Participants Octogenarian patients undergoing elective SAVR or TAVI and willing to participate in the study were eligible. Patients unable to speak Norwegian were excluded. Between 2011 and 2013, 143 consecutive patients were included, and data from 136 of them are presented.

Primary outcome Delirium.

Results Logistic regression analysis shows that lower cognitive function was positively associated with delirium (OR $0.86, \mathrm{Cl} 0.74$ to $0.99, \mathrm{p}=0.047$ ). Besides, the interaction term in the model shows that IUC use and delirium differed between SAVR and TAVI patients $(p=0.04)$. The difference corresponded to a weaker association between hours of IUC use and delirium for SAVR (OR 1.01, Cl: 0.99 to $1.03, p=0.54$ ) compared with that for TAVI (OR 1.04, Cl: 1.01 to $1.08, \mathrm{p}=0.004$ ). Conclusions The association between IUC use and delirium is stronger for octogenarian patients treated with TAVI than for patients who received SAVR. Our results revealed a previously unknown association between the number of hours an IUC is used and postoperative delirium in octogenarian patients treated with TAVI.

\section{INTRODUCTION}

Surgical aortic valve replacement (SAVR) and transcatheter aortic valve implantation (TAVI) are cardiac procedures often performed in patients 80 years old and older. ${ }^{1}$ However, in this patient group the need for general anaesthesia, sternotomy and cardiopulmonary bypass-which is required with SAVR - might represent an excessive operative threat. TAVI is a minimally invasive treatment option and the treatment of choice for patients who have a higher operative risk.

\section{Strengths and limitations of this study}

- This is the first study aiming to identity possible differences in the association between length of time of IUC use and delirium in octogenarian patients undergoing aortic valve therapy with SAVR or TAVI.

- The fact that very few patients declined consent to participation or went unidentified before treatment give us confidence that our study is robust against patient selection bias, and therefore, provides a sturdy foundation for policy guidance and direction for future studies.

- Despite having a relatively low number of included patients, the data from this study includes a geographical area covering a population of more than 1300000 , giving us confidence that our results reasonably reflect the octogenarian population of a large urban area in a modern western country.

- The results presented in this study are based on a secondary analysis of previously collected data of a completed observational study.

TAVI is also a better choice for patients who are not suited for SAVR. ${ }^{23}$

During cardiac procedures, monitoring of urine output may provide important clinical information on haemodynamics. An indwelling urinary catheter (IUC) is typically used during SAVR, because haemodynamic and renal events associated with open-heart surgery are complex. The early adoption of surgical practices in TAVI programmes has resulted in use of IUCs in a similar way as that for SAVR, even though TAVI is a shorter procedure and has minimal clinical disruptions. ${ }^{4}$ This raises questions about whether IUC use might be safely avoided, or greatly modified, for TAVI patients. Although practices continue to evolve, across many centres IUCs continue to be frequently used for TAVI, and IUC remains a standard of care for SAVR. However, IUC use does not come without challenges. It is associated with more hospital 
complications, such as delirium and longer length of hospital stay and worse clinical outcomes. ${ }^{45}$

Postoperative delirium is a common hospital complication in older patients. ${ }^{6}$ Delirium is defined as an acute and fluctuating change in attention and $\operatorname{cognition}^{7}$ that can lead to functional and cognitive decline. ${ }^{8-10}$ The pathophysiology of delirium is not fully understood, but it has been established that a complex interrelationship between predisposing factors (age $\geq 75$, cognitive and functional impairment, and comorbidities) and precipitating factors (surgery, infections and physical restrains) contribute to its development. ${ }^{6}$

Delirium that emerges after SAVR and TAVI has been associated with undesirable outcomes in octogenarian patients. ${ }^{11-13}$ Previous studies show that IUC use might be linked to delirium in hospitalised medical patients 70 years old and older. ${ }^{814-16}$ Urinary catheters have also been associated with a higher incidence of delirium in older hospitalised patients with cardiac diseases. ${ }^{17}$ Due to the less invasive nature of TAVI, the majority of patients receiving TAVI may require IUCs for shorter periods than patients receiving SAVR, or the practice may be re-examined with the increasing adoption of minimalist strategies. To the best of our knowledge, no study has investigated the use of IUCs and a possible association with delirium in octogenarian patients after SAVR or TAVI. The aim of the present study was therefore to determine whether an association exists between delirium and IUC use in octogenarian patients treated with SAVR or TAVI.

\section{METHODS}

\section{Study design, settings and participants}

This study presents secondary analyses of data gathered in the Delirium in Octogenarians Undergoing Cardiac Surgery or Intervention (CARDELIR) study. CARDELIR is an observational, prospective cohort study of consecutive patients undergoing elective SAVR or TAVI in a tertiary university hospital. All SAVR and TAVI procedures in the western part of Norway are performed at this university hospital, which covers an extensive geographic area and a big population group. ${ }^{18}$ Inclusion criteria were: (1) age of 80 years and older, (2) previous acceptance for aortic valve treatment with SAVR or TAVI and (3) willingness to participate in the study. Exclusion criteria were inability to speak Norwegian or denied consent to participate. The presence or absence of delirium was the primary outcome of CARDELIR. A heart team comprised experts in cardiothoracic surgery and invasive cardiology evaluated octogenarian patients with aortic stenosis and identified those suited for SAVR or TAVI based on current guidelines at the time of the study. ${ }^{19}$ SAVR is an invasive procedure that requires general anaesthesia, sternotomy and extracorporeal circulation..$^{20}$ TAVI was initially designed for high-risk patients, not suitable to SAVR. ${ }^{21}$ TAVI is less aggressive and can be performed without sternotomy or cardiopulmonary bypass. ${ }^{20}{ }^{21}$ A power analysis calculation for the original study showed that including 84 patients treated with SAVR and 65 patients receiving TAVI would give a power of $89 \%$ to detect delirium. ${ }^{18}$

Elective SAVR or TAVI was performed in 162 octogenarian patients between February 2011 and August 2013. Fifteen patients did not meet the inclusion criteria; three other patients were excluded, because we failed to identify them before surgery or intervention due to administrative reasons. This left a total of 144 patients who agreed to participate in CARDELIR; however, one of them withdrew consent before treatment, and seven more could not be assessed for delirium because they were non-responsive after surgery or had died. Accordingly, this study presents data for 136 patients, $63(46 \%)$ of them were treated with TAVI. A patient was classified as having experienced delirium if delirium had been identified at least once between the first and fifth postoperative day.

\section{Variables}

\section{Delirium}

The presence/absence of delirium was identified with the Confusion Assessment Method (CAM). ${ }^{22}$ CAM is an instrument based on the Diagnostic and Statistical Manual of Mental Disorders (DSM-IV) that captures the four core features of delirium, which include (1) acute onset and fluctuating course, (2) inattention, (3) disorganised thinking and (4) altered level of consciousness. The presence of delirium is established when features (1) and (2) are present, and either (3) or (4) are displayed. ${ }^{22}$

\section{Duration of IUC use}

The IUC was inserted immediately prior to SAVR or TAVI, and information about the length of time (in hours) a patient had an IUC was retrieved from medical records.

\section{Other relevant variables}

Cognitive function

The Mini-Mental State Examination was used to evaluate baseline general cognitive functioning of patients. ${ }^{23}$ This instrument produces a score between $0-30$ points, with 30 indicating the highest level of cognition. ${ }^{23}$

\section{Functional independence}

The functional independence of patients was evaluated with the Barthel Index. This index assesses self-care abilities in feeding, bathing, grooming, dressing, bowel, bladder, toilet use, transferring, walking, and using stairs. ${ }^{24}$ The highest achievable score on the index is 20 , with a score of 19 representing functional independence. ${ }^{24}$

\section{Comorbidities}

Preoperative comorbidities were quantified with the Charlson Comorbidity Index. ${ }^{25}$ This index predicts mortality by assigning values to different comorbidity disorders, and by adding up the values to produce a sum score. Higher scores represent higher risk of mortality. ${ }^{25}$

Other potential factors associated with the development of delirium (atrial fibrillation and infections) were based on literature review ${ }^{626}$ and on clinical experience. 


\section{Data collection}

A detailed description of preoperative data collection and assessment of delirium has been presented earlier. ${ }^{18}$ In short, patients fulfilling the inclusion criteria were approached the day before SAVR or TAVI, and informed consent was obtained. Experienced members of the research team performed assessment of cognitive function and functional independence after inclusion. Medical records and interviews with patients provided demographic information and clinical data.

Delirium was assessed from the first to the fifth postoperative day at approximately the same time of the day (noon). To strengthen inter-rater reliability, only members of the research team having several years of experience with cardiac and geriatric patients, and trained in the use of CAM, performed the delirium assessment. Nursing staff at the cardiothoracic surgery department received information about the features of delirium on a regular basis and were encouraged to report delirium symptoms at every shift. Medical, nursing, and physiotherapy reports from the previous 24 hours and results from meetings with health professionals caring for the patients were also considered when the CAM was scored.

Patients undergoing SAVR or TAVI received prophylactic antibiotics following an identical regimen. Cephalosporin (Cefalotin) was administered every $90 \mathrm{~min}$ during the procedure. Treatment continued during the first postoperative day every 6 hours, with a maximum of five doses.

All participants had an IUC inserted immediately prior to the start of the SAVR or TAVI procedure. Hospital protocols prescribe IUC removal within 24 hours after surgery for clinically stable patients treated with SAVR, whereas protocols for clinically stable patients treated with TAVI prescribe the removal of the IUC the same day the procedure is performed.

\section{Statistical methods}

Data are presented as counts and percentages, or means and SD/CI. Pearson's $\chi^{2}$ test was used to compare treatment groups (SAVR vs TAVI and Delirium vs non-delirium) and categorical variables. Comparisons between treatment groups and continuous variables were performed using Welch's $t$-test (a $t$-test that does not assume equal variances across groups). The association between risk factors for delirium (including length of time of IUC use) in patients following aortic valve replacement was evaluated with logistic regression. The logistic model also included an interaction term between type of aortic valve treatment (SAVR/TAVI) and length of time of IUC use. This allowed us to examine whether the association between length of time of IUC use and delirium differed between the two treatment types. Data management and statistical analyses were performed in SPSS (IBM SPSS Statistics for Windows, V.24.0) and R V.3.4.0. ${ }^{27}$

\section{Ethical considerations}

The study was conducted in accordance with the Declaration of Helsinki. Special consideration was given to behavioural indicators of patient exhaustion during data collection. Whenever these signs were present, data collection was stopped and resumed later.

\section{Patient and public involvement}

No patients were involved in the design or implementation of this study. However, CARDELIR has provided data for several quantitative ${ }^{182829}$ and qualitative studies ${ }^{30} 31$ having patient-reported outcomes. The results of these papers have been extended to the patient community through patient organisations and open lectures.

\section{RESULTS \\ Characteristics of the study population and development of delirium}

The majority (56\%) of patients were females, and $46 \%$ of the cohort received TAVI. Patients in the TAVI group were older ( 85 vs 82 years old, $\mathrm{p}<0.001$ ); had more comorbidities (2.5 vs 1.8, p=0.001); and had higher logistic EuroSCOREs (19.6 vs 9.4, $\mathrm{p}<0.001$ ). Table 1 summarises other characteristics of the participants, stratified by SAVR or TAVI.

New episodes of delirium occurred at least once in $56 \%$ of the octogenarian patients during the 5-day study period. Of the patients in the SAVR group, $66 \%$ developed delirium compared with $44 \%$ of patients in the TAVI group $(\mathrm{p}=0.01)$, but the average number of days patients experienced delirium did not differ significantly between SAVR and TAVI patients $(\mathrm{p}=0.20) .{ }^{18}$

\section{Aortic valve treatment type, duration of IUC use and delirium}

The average duration of IUC use in the total sample was 54 hours (SD 31, range 18-120 hours). On average, patients with delirium used an IUC for 63 hours $(\mathrm{SD}=33)$, whereas patients without delirium used an IUC for 43 hours $(\mathrm{SD}=25)(\mathrm{p}<0.001)$.

The length of time of IUC use in SAVR patients with delirium was, on average, 66 hours $(\mathrm{SD}=29)$, compared with 59 hours $(\mathrm{SD}=27)$ for $\mathrm{SAVR}$ patients without delirium $(p=0.31)$. The length of time of IUC use in patients treated with TAVI and with delirium was, on average, 58.5 hours (SD 38.2), while TAVI patients without delirium used an IUC, on average, 31.6 hours ( $\mathrm{SD}=15.1 ; \mathrm{p}=0.001$ ) (table 2 ).

\section{Interaction analysis}

The logistic regression model that included an interaction term (SAVR/TAVI ×length of time of IUC use) showed a significant association with lower cognitive scores (MMSE) (OR 0.86, CI: 0.74 to 0.99, $\mathrm{p}=0.047$ ), and a significant interaction between length of time of IUC use and treatment type $(p=0.003)$. This interaction corresponds to an association between hours of IUC use and delirium of OR 1.04 (CI: 1.00 to $1.08, \mathrm{p}=0.04$ ) for TAVI (table 3 and figure 1). 
Table 1 Characteristics of octogenarian patients undergoing surgical aortic valve replacement (SAVR) or transcatheter aortic valve implantation (TAVI) $(n=136)$

\begin{tabular}{|c|c|c|c|c|}
\hline & Total $n=136$ & SAVR $n=73(54 \%)$ & TAVI $n=63(46 \%)$ & \\
\hline Variables & $\begin{array}{l}\text { Count } / \text { mean } \\
\pm \mathrm{SD} \text { or (percentage) }\end{array}$ & $\begin{array}{l}\text { Count } / \text { mean } \\
\pm \mathrm{SD} \text { or (percentage) }\end{array}$ & $\begin{array}{l}\text { Count/mean } \\
\pm \mathrm{SD} \text { or (percentage) }\end{array}$ & $P$ values \\
\hline Age (years), mean SD & $83.5 \pm 2.7$ & $82 \pm 2.1$ & $85 \pm 2.8$ & $<0.001$ \\
\hline Female n (\%) & $76(55.9)$ & $36(49.3)$ & $40(63.5)$ & 0.09 \\
\hline MMSE, mean SD (range 0-30) & $27.2 \pm 2.9$ & $27.8 \pm 2.6$ & $26.5 \pm 3.1$ & 0.01 \\
\hline $\begin{array}{l}\text { Charlson Comorbidity Index, mean } \\
\text { SD }\end{array}$ & $2.1 \pm 1.2$ & $1.8 \pm 0.9$ & $2.4 \pm 1.3$ & 0.01 \\
\hline Logistic EuroScore & $14.0 \pm 9.2$ & $9.2 \pm 3.4$ & $19.6 \pm 10.6$ & $<0.001$ \\
\hline NYHA functional class & & & & $<0.001$ \\
\hline I+II (\%) & $47(34.6)$ & $37(54.4)$ & $10(18.5)$ & \\
\hline III+IV (\%) & $75(55.1)$ & $31(45.6)$ & $44(81.5)$ & \\
\hline LVEF (\%) & $56.6 \pm 10.2$ & $57.2 \pm 10.3$ & $55.8 \pm 10.2$ & 0.41 \\
\hline Max aorta gradient $(\mathrm{mm} \mathrm{Hg})$ & $79.5 \pm 23.9$ & $83.5 \pm 24.7$ & $75 \pm 22.4$ & 0.04 \\
\hline Mean aorta gradient $(\mathrm{mm} \mathrm{Hg})$ & $48.3 \pm 16.1$ & $50.7 \pm 16.3$ & $46 \pm 15.8$ & 0.08 \\
\hline ASA Classification & & & & $<0.001$ \\
\hline III (yes) & $114(83.8)$ & 71 (97.3) & 43 (68.3) & \\
\hline IV (yes) & $22(16.2)$ & $2(2.7)$ & $20(31.7)$ & \\
\hline Delirium (yes) & 76 (55.9) & $48(65.8)$ & $28(44.4)$ & 0.01 \\
\hline
\end{tabular}

ASA, American Society of Anesthesiologist Physical Status Classification System; BMI, body mass index; IADL, instrumental activities of daily living; LVEF, Left ventricle ejection fraction; MMSE, Mini Mental State Examination; NYHA, New York Heart Association Functional Classification.

\section{DISCUSSION}

To the best of our knowledge, this is the first study that shows an association between length of time an IUC is used and incidence of delirium in octogenarian patients treated with TAVI. Our main findings were that patients with delirium had used an IUC for a significantly longer time than patients without delirium, and that the association between IUC use was stronger for TAVI patients than for SAVR patients (figure 1). Our results are clinically relevant, considering the increasing number of octogenarian patients receiving advanced cardiac procedures such as SAVR and TAVI. Moreover, these findings should

Table 2 Univariate analysis of variables associated with postoperative delirium in octogenarian patients following aortic valve replacement $(n=136)$

\begin{tabular}{|c|c|c|c|c|c|c|c|}
\hline \multirow[b]{2}{*}{ Characteristic } & \multirow[b]{2}{*}{$\begin{array}{l}\text { Total } \mathrm{n}=25 \\
\text { Count/ } \\
\text { mean } \pm \text { SD or } \\
\text { (percentage) }\end{array}$} & \multicolumn{2}{|l|}{ SAVR, $n=73$} & \multirow[b]{2}{*}{ P values } & \multicolumn{2}{|l|}{ TAVI $n=63$} & \multirow[b]{2}{*}{ P values } \\
\hline & & $\begin{array}{l}\text { Delirium, } \mathrm{n}=25 \\
\text { Count/ } \\
\text { mean } \pm \text { SD or } \\
\text { (percentage) }\end{array}$ & $\begin{array}{l}\text { No Delirium, } \\
\mathrm{n}=48 \text { Count/ } \\
\text { mean } \pm S D \text { or } \\
\text { (percentage) }\end{array}$ & & $\begin{array}{l}\text { No delirium, } \\
\mathrm{n}=35 \text { Count/ } \\
\text { mean } \pm \text { SD or } \\
\text { (percentage) }\end{array}$ & $\begin{array}{l}\text { Delirium, } \\
\mathrm{n}=28 \text { Count/ } \\
\text { mean } \pm \mathrm{SD} \text { or } \\
\text { (percentage) }\end{array}$ & \\
\hline Age (years), mean SD & $83.5 \pm 2.7$ & $81.6 \pm 1.4$ & $82.7 \pm 2.3$ & 0.01 & $84.7 \pm 2.8$ & $84.9 \pm 2.8$ & 0.74 \\
\hline Female, n (\%) & 76 (55.9) & $12(48)$ & $24(50)$ & 0.87 & 25 (71.4) & 15 (53.6) & 0.14 \\
\hline $\begin{array}{l}\text { Barthel Index, mean SD } \\
\text { (range 0-20) }\end{array}$ & $18.9 \pm 1.5$ & $19.5 \pm 1.0$ & $18.9 \pm 1.5$ & 0.06 & $18.9 \pm 1.5$ & $18.5 \pm 1.4$ & 0.28 \\
\hline $\begin{array}{l}\text { MMSE, mean SD (range } \\
0-30 \text { ) }\end{array}$ & $27.2 \pm 2.9$ & $27.9 \pm 2.2$ & $27.8 \pm 2.8$ & 0.86 & $27.4 \pm 2.4$ & $25.4 \pm 3.6$ & 0.01 \\
\hline $\begin{array}{l}\text { Charlson Comorbidity } \\
\text { Index, mean } \pm \text { SD }\end{array}$ & $2.1 \pm 1.2$ & $1.8 \pm 1.0$ & $1.8 \pm 0.9$ & 0.78 & $2.3 \pm 1.3$ & $2.7 \pm 1.3$ & 0.20 \\
\hline Infections (yes), n (\%) & 48 (35.3) & $5(20)$ & 15 (31.3) & 0.30 & 13 (37.1) & 15 (53.6) & 0.19 \\
\hline $\begin{array}{l}\text { Length of time of IUC use } \\
\text { (hours), mean SD }\end{array}$ & $54 \pm 31$ & $59 \pm 27$ & $66.1 \pm 29.3$ & 0.31 & $31.6 \pm 15.1$ & $58.5 \pm 38.2$ & 0.001 \\
\hline
\end{tabular}

IUC use, Indwelling urine catheter use; MMSE, Mini Mental State Examination; SAVR, Surgical aortic valve replacement; TAVI, transcatheter aortic valve implantation. 
Table 3 Logistic regression model showing interaction effect between type of treatment and length of IUC use (hours) on postoperative delirium $(n=136)$

\begin{tabular}{|c|c|c|c|c|c|c|}
\hline & \multicolumn{3}{|c|}{ Unadjusted } & \multicolumn{3}{|c|}{ Adjusted } \\
\hline & OR & $95 \% \mathrm{Cl}$ & P values & OR & $95 \% \mathrm{Cl}$ & P values \\
\hline Gender & & & 0.23 & & & 0.84 \\
\hline \multicolumn{7}{|l|}{ Male (ref.) } \\
\hline Female & 0.66 & 0.33 to 1.30 & & 0.92 & 0.41 to 2.10 & \\
\hline Barthel Index (range 0-20) & 0.82 & 0.63 to 1.04 & 0.10 & 0.74 & 0.54 to 1.00 & 0.06 \\
\hline Atrial fibrillation & & & 0.22 & & & 0.11 \\
\hline \multicolumn{7}{|l|}{ No (ref.) } \\
\hline Yes & 1.61 & 0.76 to 3.53 & & 2.18 & 0.86 to 5.83 & \\
\hline Charlson Comorbidity Index & 1.02 & 0.76 to 1.37 & 0.91 & 1.03 & 0.73 to 1.48 & 0.86 \\
\hline MMSE score & 0.92 & 0.81 to 1.03 & 0.15 & 0.86 & 0.74 to 0.99 & 0.05 \\
\hline Length IUC use (hours) & 1.013 & 1.01 to 1.04 & $<0.001$ & 1.01 & 0.99 to 1.03 & 0.54 \\
\hline Postoperative infections & & & 0.25 & & & 0.27 \\
\hline \multicolumn{7}{|l|}{ No (ref.) } \\
\hline Yes & 1.52 & 0.75 to 3.16 & & 1.63 & 0.68 to 4.03 & \\
\hline Treatment & & & 0.01 & & & 0.003 \\
\hline \multicolumn{7}{|l|}{ SAVR (ref.) } \\
\hline TAVI & 0.42 & 0.21 to 0.83 & & 0.06 & 0.01 to 0.35 & \\
\hline Length IUC use (hours)×treatment type & - & & & 1.04 & 1.00 to 1.08 & 0.04 \\
\hline
\end{tabular}

IUC use, Indwelling urine catheter use; MMSE, Mini Mental State Examination; ref, reference; SAVR, Surgical aortic valve replacement; TAVI, transcatheteraortic valve implantation.

give new guidance for policy that will allow hospitals to provide better healthcare to the complex group that geriatric patients represent. ${ }^{32}$

The present study has several aspects that contribute positively to clinical knowledge on the association between delirium and length of time IUC is used among octogenarian patients treated with SAVR or TAVI. Among the strengths of the study is the inclusion of consecutively admitted octogenarian patients undergoing aortic valve treatment. Very few patients declined consent to

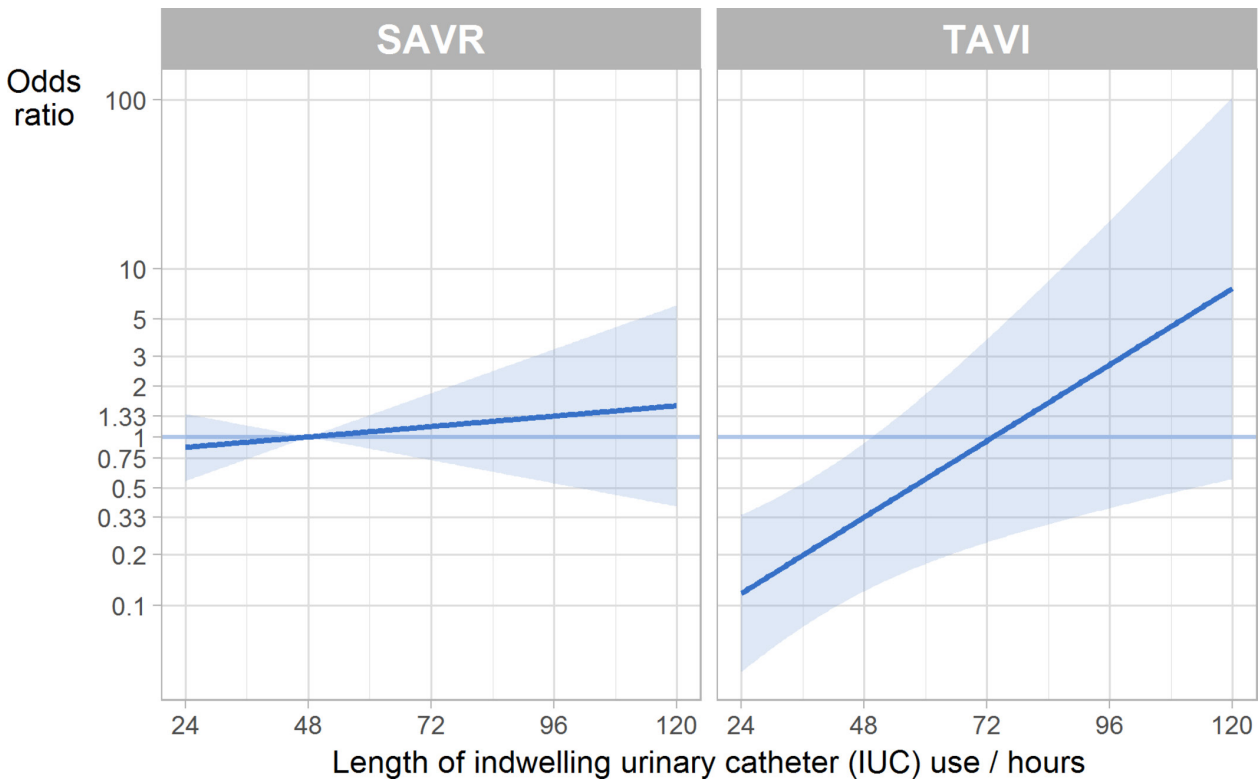

Figure 1 Estimated ORs (with 95\% point-wise $\mathrm{Cl}$ ) for the association between postoperative delirium (response) and surgery type and hours of indwelling urinary catheter use (explanatory variables) for octogenarian patients undergoing surgical aortic valve replacement (SAVR) and transcatheter aortic valve implantation (TAVI). The reference level has been set to SAVR and 48 hours (the median number of hours of IUC use in the whole population) ( $n=136)$. 
participation $(6 \%)$, and fewer than $2 \%$ of the consecutive series of patients went unidentified before treatment. These aspects give us confidence that our study is robust against patient selection bias, and therefore, provides a sturdy foundation for policy guidance and direction for future studies. We are also confident that our objective assessment of delirium was reasonable. Patients' delirium was measured using a well-accepted, valid and reliable instrument, ${ }^{22}$ and it was performed by experienced research team members having several years of care experience with geriatric and cardiac patients. We believe that our results reasonably reflect the old population of a large urban area in a modern western country. Despite having a relatively low number of included patients, the data from this study is based on a geographical area covering a population of more than $1300000 .^{18}$

However, our findings should be interpreted with caution due to several limitations. First, the present results are based on a secondary analysis of previously collected data of a completed observational study that was not a randomised controlled trial (RCT). Thus, all general caveats relevant to a non-RCT apply here also. This being said, randomisation was not possible in the original study, because SAVR and TAVI are used to treat different patient populations, ${ }^{33}$ and it would be unethical to randomise this factor. Even though we did our best to identify confounding factors, as always, unknown confounding factors could have also influenced our results. Despite recent advances in delirium, its pathophysiology remains to be fully understood, and the use of IUCs in octogenarian patients might only represent an additional piece in the delirium 'puzzle'. Our modest sample size and power considerations limited the number of variables we could include in the regression analysis, representing a limitation of our study.

Surgical procedures, such as SAVR, demand closer monitoring of patients' urine output during the operative and postoperative phase. However, unnecessary and prolonged use of IUCs can lead to undesirable effects. Bladder catheters, for example, have been linked to delirium in hospitalised patients 70 years old and older. ${ }^{81416}$ As shown in table 2, SAVR patients who later developed delirium used IUCs on average 8 hours longer than TAVI patients who also developed the condition. Yet, on further analysis, we revealed a previously unknown association between the number of hours an IUC is used and delirium in octogenarian patients treated with TAVI. This association shows an estimated $4 \%$ increased odds for delirium for each hour TAVI patients had used an IUC, compared with $1 \%$ increased odds for SAVR patients. This suggests that patients treated with TAVI and without complications, possibly could benefit if they used an IUC for a shorter periods of time ${ }^{4}$ or from the avoidance of this device. ${ }^{34}$

It has been postulated that delirium emerges as a consequence of (1) definable major events, and (2) an abnormal response to different stressors. ${ }^{35}$ SAVR might be an example of a major event that can eventually lead to delirium. SAVR demands general anaesthesia, sternotomy and extracorporeal circulation. These procedures might contribute to an excessive strain in a group of octogenarian patients. In other cases, delirium might be activated by an abnormal reaction to a minor event. ${ }^{35}$ Unnecessary or extended use of an IUC might be an example of a minor event. Octogenarian patients in the TAVI group had several baseline risk factors for delirium (older, more comorbidities, lower cognitive scores) that, together with the prolonged use of IUCs, might have triggered delirium. Yet, the invasive nature of SAVR compared with TAVI could even up these risk factors. It should be mentioned that in our patient group, delirium could emerge both before and after IUC removal. Taking this into consideration, further analyses of preoperative biomarkers of stress, such as cortisol, in patients treated with SAVR and TAVI could provide valuable information.

IUC use might contribute to, or sustain, already elevated postoperative inflammation. The role that inflammation plays in the development of delirium has been highlighted in recent years. ${ }^{36}$ A study with TAVI patients found that avoidance of IUC use was associated with significantly lower rates of urinary tract infections requiring antibiotics, haematuria and bladder irrigation. ${ }^{4}$ Even when IUC implantation was less than 24 hours, this study found negative outcomes in patients using IUC. ${ }^{4}$ Even though completely avoiding the use of an IUC is currently not possible in patients treated with SAVR, further studies should evaluate whether the length of time an IUC is used could be reduced in clinically stable SAVR patients after the procedure is performed. Studies should also evaluate whether IUC use could be avoided entirely in TAVI patients.

Infections can precipitate delirium, ${ }^{6}$ and the use of an IUC has been linked to urinary tract infections. ${ }^{37}$ Our results show that patients with delirium, independent of SAVR or TAVI treatment, used an IUC for longer than 2 days. However, no association between infections and delirium was identified with either univariate or multivariate regression analysis (tables 2 and 3 ). This suggests that when delirium was present in our octogenarian patients, the concurrent presence of an infection cannot explain the emergence of delirium.

Guidelines in the prevention and treatment of postoperative delirium recommend patient mobility and avoidance of physical restrains. ${ }^{36}$ In some cases, patient mobility can be compromised when healthcare institutions intent to prevent falls. ${ }^{38}$ Physical restraints are also linked to the emergence of delirium in intensive care units. ${ }^{6}$ In SAVR and TAVI patients, IUCs and cardiac monitoring devices keep patients from moving freely. However, it is interesting to see that the association between length of use of IUC and delirium is weaker in SAVR patients. As previously mentioned, when compared with TAVI, patients treated with SAVR had several factors that could compromise mobility even further: cardiac monitoring devices, central venous catheter, IV lines and oxygen masks. Besides, the invasive nature of the surgery 
might limit mobilisation in a stronger way than in octogenarians undergoing TAVI.

In conclusion, the length of time an IUC is used is positively correlated with postoperative delirium in octogenarian patients with severe aortic stenosis and treated with TAVI. Additional studies with similar populations are required to identify all the variables connected to the emergence of delirium in older cardiac patients, including what comprises minor and major events that precipitate this abnormal response to stressors.

\section{Author affiliations}

${ }^{1}$ Department of Health and Social Sciences, Western Norway University of Applied Sciences, Bergen, Norway

${ }^{2}$ Department of Clinical Science, University of Bergen, Bergen, Norway

${ }^{3}$ Kavli Research Center for Geriatrics and Dementia, Haraldsplass Hospital, Bergen, Norway

${ }^{4}$ Centre for Heart Valve Innovation, St. Paul's Hospital, Vancouver, Canada

${ }^{5}$ University of British Columbia, Vancouver, Canada

${ }^{6}$ Department of Heart Disease, Haukeland University Hospital, Bergen, Norway

${ }^{7}$ Centre for Clinical Research, Haukeland University Hospital, Bergen, Norway

${ }^{8}$ Department of Cardiology, Stavanger University Hospital, Stavanger, Norway

Contributors LSPE, AHR, JEN, TMN: study concept and design. LSPE: data collection. LSPE, KOH, AHR, RH, BF, SL, KKJK, JEN, TMN: analysis and interpretation of data. LSPE, AHR, SL, BF, TMN: initial draft of manuscript. LSPE, AHR, BF, SL, RH $\mathrm{KOH}, \mathrm{KKJK}$, JEN, TMN: critical revision of manuscript. LSPE, TMN and KOH had full access to all of the data (including statistical reports and tables) in the study and take responsibility for the integrity of the data and the accuracy of the data analysis.

Funding This work was supported by a full research grant from the University of Bergen to LSPE. The study also received funding from Western Norway University of Applied Sciences, the Norwegian Nurses Association, and Kavli Research Center for Geriatrics and Dementia.

Competing interests None declared.

Patient consent Not required.

Ethics approval Regional Committee for Ethics in Medical Research in Norway (REK Vest 2010/2936-6).

Provenance and peer review Not commissioned; externally peer reviewed.

Data sharing statement № additional data available.

Open access This is an open access article distributed in accordance with the Creative Commons Attribution Non Commercial (CC BY-NC 4.0) license, which permits others to distribute, remix, adapt, build upon this work non-commercially, and license their derivative works on different terms, provided the original work is properly cited, appropriate credit is given, any changes made indicated, and the use is non-commercial. See: http://creativecommons.org/licenses/by-nc/4.0/.

\section{REFERENCES}

1. Scandroglio AM, Finco G, Pieri M, et al. Cardiac surgery in 260 octogenarians: a case series. BMC Anesthesiol 2015;15:15:15.

2. Smith $\mathrm{CR}$, Leon MB, Mack MJ, et al. Transcatheter versus surgical aortic-valve replacement in high-risk patients. $N$ Engl J Med 2011;364:2187-98.

3. Barker CM, Reardon MJ. The CoreValve US pivotal trial. Semin Thorac Cardiovasc Surg 2014;26:179-86.

4. Lauck SB, Kwon JY, Wood DA, et al. Avoidance of urinary catheterization to minimize in-hospital complications after transcatheter aortic valve implantation: An observational study. Eur J Cardiovasc Nurs 2018;17:66-74.

5. Chant C, Smith OM, Marshall JC, et al. Relationship of catheterassociated urinary tract infection to mortality and length of stay in critically ill patients: a systematic review and meta-analysis of observational studies. Crit Care Med 2011;39:1167-73.

6. Inouye SK, Westendorp RG, Saczynski JS. Delirium in elderly people. Lancet 2014;383:911-22.

7. European Delirium AssociationAmerican Delirium Society. The DSM5 criteria, level of arousal and delirium diagnosis: inclusiveness is safer. BMC Med 2014;12:141.
8. Dharmarajan K, Swami S, Gou RY, et al. Pathway from delirium to death: potential in-hospital mediators of excess mortality. J Am Geriatr Soc 2017;65:1026-33.

9. Koster S, Hensens AG, Schuurmans MJ, et al. Consequences of delirium after cardiac operations. Ann Thorac Surg 2012;93:705-11.

10. Rudolph JL, Marcantonio ER. Review articles: postoperative delirium: acute change with long-term implications. Anesth Analg 2011;112:1202-11

11. Eide LS, Ranhoff $A H$, Fridlund $B$, et al. Delirium as a predictor of physical and cognitive function in individuals aged 80 and older after transcatheter aortic valve implantation or surgical aortic valve replacement. J Am Geriatr Soc 2016;64:1178-86.

12. Eide LS, Ranhoff $A H$, Fridlund $B$, et al. Readmissions and mortality in delirious versus non-delirious octogenarian patients after aortic valve therapy: a prospective cohort study. BMJ Open 2016;6:e012683.

13. Mangusan RF, Hooper V, Denslow SA, et al. Outcomes associated with postoperative delirium after cardiac surgery. Am J Crit Care 2015;24:156-63.

14. Inouye SK, Charpentier PA. Precipitating factors for delirium in hospitalized elderly persons. Predictive model and interrelationship with baseline vulnerability. JAMA 1996;275:852-7.

15. Van Rompaey B, Elseviers MM, Schuurmans MJ, et al. Risk factors for delirium in intensive care patients: a prospective cohort study. Crit Care 2009;13:R77.

16. Dingwall L, McLafferty E. Nurses' perceptions of indwelling urinary catheters in older people. Nurs Stand 2006;21(14-16):35-42.

17. Noriega FJ, Vidán MT, Sánchez E, et al. Incidence and impact of delirium on clinical and functional outcomes in older patients hospitalized for acute cardiac diseases. Am Heart $J$ 2015;170:938-44.

18. Eide LS, Ranhoff AH, Fridlund B, et al. Comparison of frequency, risk factors, and time course of postoperative delirium in octogenarians after transcatheter aortic valve implantation versus surgical aortic valve replacement. Am J Cardiol 2015;115:802-9.

19. Vahanian A, Alfieri O, Andreotti F, et al. Guidelines on the management of valvular heart disease (version 2012): the Joint Task Force on the Management of Valvular Heart Disease of the European Society of Cardiology (ESC) and the European Association for Cardio-Thoracic Surgery (EACTS). Eur J Cardiothorac Surg 2012;42:S1-44.

20. Martin E, Dagenais F, Voisine P, et al. Surgical aortic valve replacement outcomes in the transcatheter era. J Thorac Cardiovasc Surg 2015;150:1582-8.

21. Leon MB, Smith CR, Mack M, et al. Transcatheter aortic-valve implantation for aortic stenosis in patients who cannot undergo surgery. N Engl J Med 2010;363:1597-607.

22. Inouye SK, van Dyck CH, Alessi CA, et al. Clarifying confusion: the confusion assessment method. A new method for detection of delirium. Ann Intern Med 1990;113:941-8.

23. Folstein MF, Folstein SE, McHugh PR. "Mini-mental state". A practical method for grading the cognitive state of patients for the clinician. J Psychiatr Res 1975;12:189-98.

24. Mahoney FI, Barthel DW. Functional evaluation: the barthel index. Md State Med J 1965;14:61-5.

25. Charlson ME, Pompei P, Ales KL, et al. A new method of classifying prognostic comorbidity in longitudinal studies: development and validation. J Chronic Dis 1987;40:373-83

26. Koster S, Hensens AG, Schuurmans MJ, et al. Risk factors of delirium after cardiac surgery: a systematic review. Eur J Cardiovasc Nurs 2011;10:197-204.

27. Team RC. R: a language and environment for statistical computing Vienna, Austria: R Foundation for Statistical Computing, 2017

28. Eide LS, Ranhoff AH, Fridlund B, et al. Delirium as a Predictor of Physical and Cognitive Function in Individuals Aged 80 and Older After Transcatheter Aortic Valve Implantation or Surgical Aortic Valve Replacement. J Am Geriatr Soc 2016;64:1178-86.

29. Olsen SJ, Fridlund B, Eide LS, et al. Changes in self-reported health and quality of life in octogenarian patients one month after transcatheter aortic valve implantation. Eur J Cardiovasc Nurs 2017;16:79-87.

30. Instenes I, Gjengedal E, Eide LSP, et al. "Eight Days of Nightmares ... " - Octogenarian Patients' Experiences of Postoperative Delirium after Transcatheter or Surgical Aortic Valve Replacement. Heart Lung Circ 2018;27:260-6.

31. Instenes I, Fridlund B, Eide LS, et al. A qualitative study on how octogenarians experience relatives and health professionals when being in a delirious state after aortic valve therapy. Eur $J$ Cardiovasc Nurs 2017;16.

32. Bell SP, Orr NM, Dodson JA, et al. What to expect from the evolving field of geriatric cardiology. J Am Coll Cardiol 2015;66:1286-99. 
33. Makkar RR, Fontana GP, Jilaihawi $\mathrm{H}$, et al. Transcatheter aortic-valve replacement for inoperable severe aortic stenosis. N Engl J Med 2012;366:1696-704.

34. Lauck SB, Wood DA, Baumbusch J, et al. Vancouver Transcatheter Aortic Valve Replacement Clinical Pathway: Minimalist Approach, Standardized Care, and Discharge Criteria to Reduce Length of Stay. Circ Cardiovasc Qual Outcomes 2016;9:312-21.

35. Maclullich AM, Anand A, Davis DH, et al. New horizons in the pathogenesis, assessment and management of delirium. Age Ageing 2013;42:667-74.
36. Oh ES, Fong TG, Hshieh TT, et al. Delirium in older persons: advances in diagnosis and treatment. JAMA 2017;318:1161-74.

37. Wald HL, Ma A, Bratzler DW, et al. Indwelling urinary catheter use in the postoperative period: analysis of the national surgical infection prevention project data. Arch Surg 2008;143:551-7.

38. Growdon ME, Shorr RI, Inouye SK. The tension between promoting mobility and preventing falls in the hospital. JAMA Intern Med 2017:177:759-60. 